Europe's Journal of Psychology, 8(1), pp. 18-31, doi:10.5964/ejop.v8i1.296

www.ejop.org

Criminal Attitudes, Recidivistic Behaviour, and the Mediating Role of Associations with Criminal Friends: An Empirical Investigation within a Prison Sample of Violent Offenders

\title{
Daniel Boduszek
}

University of Ulster, UK

Philip Hyland

University of Ulster, UK

Jacek Pedziszczak

Polish Prison Service, Poland

Krzysztof Kielkiewicz

All Hallows College, Ireland

\section{Abstract}

Previous studies suggested a significant interaction between criminal attitudes, associations with criminal friends, and criminal behaviour. The purpose of the current investigation was to provide the possible mediating role of associations with criminal friends between criminal attitudes, and criminal behaviour. Based on a sample of 133 violent offenders, the proposed mediation model tested was found to be a good fit of the observed data, with each of the respective fit indices exceeding the criteria for a good fitting model. Thus results suggest that the presence and influence of criminal friends has a significant mediating effect on the interaction between criminal attitudes and recidivistic behaviour. Further implications in relation to research and theory are discussed.

Keywords: Criminal behaviour, recidivism, anti-social friends, social learning theory, criminal attitudes

This is an open access article distributed under the terms of the Creative Commons Attribution License (http://creativecommons.org/licenses/by/3.0), which permits unrestricted use, distribution, and reproduction in any medium, provided the original work is properly cited. 
Learning theories, particularly social learning theories which have had the most impact on criminology (Akers, Krohn, Lanze-Kaduce, \& Radosevich, 1979), believe that criminality is a function of individual socialization, how individuals have been influenced by their experiences or relationships with family, peer groups, teachers, church, authority figures, and other agents of socialization. The Social Learning Theory is associated with the classical work of Bandura (1969) who formulated the principles of "stimulus control", outlined the stages of modelling (Bandura, 1989) and pioneered the field of "vicarious learning" (Bandura \& Walters, 1963).

The evidence suggests that most offences are committed in groups (Kaiser, 1997; Reiss \& Farrington, 1991;). According to Social Learning Theory the influence of antisocial peers is central to understanding the development of criminal behaviour and predicting criminal acts (see Conway \& McCord, 2002; Mills, Kroner \& Forth, 2002). Agnew (1991) reported that one of the most consistent findings with antisocial populations is the relationship between antisocial peers and antisocial behavior. These findings are consistent within criminological psychology (Warr, 1993), child psychology (Monahan, Steinberg, \& Cauffman, 2009), and adult psychology literature (Gendreau, Little, \& Goggin, 1996). However, research about the influence of antisocial peers on adult offenders has received relatively little attention when compared with research involving children and adolescents.

In order to understand and develop explanatory models of criminal behaviour, social learning theorists have placed great emphasis on internal cognitive processes such as memory and cognition (attitudes, beliefs, thinking styles etc.) which is a focus previously indicated by Bandura (1969). Differential association theory (Sutherland, 1947; Sutherland \& Cressey, 1978; Sutherland, Cressey \& Luckenbill, 1992) attempts to explain crime in terms of learning and, in particular, social learning. It is proposed that through associations with other people who hold favourable attitudes towards crime, individuals adopt these attitudes and learn how to commit acts of criminality. Factors crucial in this process include with whom the individual associates, the length, frequency, and personal meaningfulness of such associations, and how early in the individual's development such associations were formed. Akers (1977) proposed a social learning theory of deviance that integrates differential association theory and the principles of Skinnerian behaviourism. According to Akers' (1985) differential reinforcement theory, people are first indoctrinated into deviant behaviour through the process of differential association with deviant peers. Then, as a consequence of differential reinforcement, they learn how to reap the rewards and avoid the penalties of criminal behaviour by reference to the actual or anticipated consequences of such behaviours. This theory tends to fit well into 
criminology because it explains the decision making process involved in developing the motivation, attitudes, and techniques necessary to commit crime (Akers et al., 1979).

Thus, learning theories posit that individuals learn to engage in crime through exposure to, and adoption of, attitudes that are favourable to breaking the law (Akers, 1985; Sutherland et al., 1992). Central to this perspective is the idea that individuals who have friends who are delinquent are more likely to become delinquent themselves. These theoretical explanations have been widely regarded as one of the strongest correlates of delinquency (Agnew, 1991; Thornberry, Lizotte, Krohn, Farnworth, \& Jang, 1994; Warr, 1993, 2002, 2005; Warr \& Stafford, 1991). A meta-analysis conducted by Gendreau, Little, \& Goggin (1996) examined a broad range of predictors related to adult recidivism. Predictors of recidivism were placed into one of seventeen categories (e.g., criminal history, age, race, companions/associates, personal distress, substance abuse, etc.). The most significant predictors of adult recidivism to emerge were association with criminal peers, criminal attitudes, and adult criminal history. These findings suggest that criminal attitudes and criminal associates are closely tied both theoretically and empirically.

According to Holsinger (1999) criminal behaviour can be better understood by looking at criminal versus non-criminal populations. Simply put, people who have been socialised in a pro-social environment and have internalised pro-social attitudes toward crime are likely to be deterred from participating in criminal behaviour whereas individuals who have been socialised in an anti-social environment and have internalised antisocial attitudes toward crime are more likely to become involved with crime. Holsinger's (1999) findings suggest that individuals who held or experienced more persistent favourable attitudes, feelings, or thoughts toward crime, through their associations with criminal friends, committed more crimes than those individuals who possessed pro-social attitudes. Support for this study was provided by Bäckström and Björklund (2008) who compared Swedish criminal and non-criminal samples on all four subscales of the Measure of Criminal Attitudes and Associates (violence, entitlement, antisocial intent, associates; Mills \& Kroner, 1999) and found large mean differences between the two groups on each of the subscales. The finding that those within the criminal sample were found to possess substantially higher levels of criminal attitudes and anti-social associates as compared to the general population sample has been called into question given the much larger proportion of females in the general sample. However such strongly significant differences were still evident when the male criminal offenders were 
compared to the males in the general sample. Simourd $(1997,1999)$ and Losel $(2003)$ provided further support with findings that indicated that through interactions with group influences, delinquent adolescents develop attitudes, values, and self-related cognitions that encourage criminal behaviour.

Mills and colleagues (2002) also reported that norms and influence from criminal friends interact with criminal attitudes, and when coupled, the relationship to criminality is particular strong. Additionally, Rhodes (1979) found that people who enter prison with low levels of antisocial thoughts and attitudes develop more deviant attitudes with the passage of time. This increase in antisocial attitudes is likely due to the association with criminal peers within the prison environment.

Within social and criminological psychology, criminal attitudes have been a mainstay in the prediction of antisocial behaviour (Stevenson, Hall, \& Innes, 2003) however to date researchers have not considered the potential mediating role of criminal friends in the prediction of recidivistic behaviour. Additionally, previous research investigating criminal attitudes, criminal friends and recidivism has never considered a Polish prison sample. Therefore, in line with previous studies which suggest a significant interaction between criminal attitudes, associations with criminal friends, and criminal behaviour, this study aims to investigate the possible mediating role of associations with criminal friends between criminal attitudes, and criminal behaviour using a Polish recidivistic violent prison sample. In this study, the direct impact of the four components of criminal attitudes (Attitudes towards Violence, Sense of Entitlement, Antisocial Intent, and Attitudes toward Criminal Associates) as outlined by Mills and Kroner (1999) on association with criminal friends is investigated, along with the direct impact of association with criminal friends on criminal behaviour. However, the main focus of the study is placed on indirect effects between the four components of criminal attitudes on criminal behaviour via association with criminal friends. It is hypothesised that association between criminal attitudes and criminal behaviour is activated in the presence of criminal others. This hypothesis has never been tested within the path modelling framework using a Polish prison sample.

Method

Participants and Procedure

One hundred and thirty three ( $N=133$ ) male violent offenders incarcerated in Nowogard high security prison for recidivists participated in this study. The participants ranged in age from 20 to $66(M=33.85, S D=9.38)$. Ethical Approval for 
the study was granted by the Polish Prison Service. A brief description of the study was provided to each participant along with the questionnaire. Participants were informed about the nature of the study and were requested to complete the questionnaire. Respondents were assured about the confidentiality of their participation, and informed that they could withdraw from the study at any time. Participants completed the questionnaires in prison in their living units. The participation was voluntary without any form of reward. After completing the questionnaire, prisoners were asked to return it to the prison educational coordinator into sealed envelopes.

The translation of the Measure of Criminal Attitudes and Associates from English to Polish was performed by a team of Polish and English speaking researchers. First, principal researcher translated the measures into Polish. Polish version was then sent to Polish Prison Service (PPS) for their approval, and appropriate member of PPS translated Polish versions back into English. Both translations of measures, together with the original English versions, were then submitted to 3 experts who indicated appropriate changes.

\section{Measures}

The Measure of Criminal Attitudes and Associates (MCAA; Mills \& Kroner, 1999) is a twopart self-report measure of criminal attitudes and associates. Part $A$ is a measure intended to quantify criminal associations. Respondents are asked to recall the four adults with they spend most of their free time with 10\%-25\%, 25\%-50\%, 50\%-75\%, 75\%$100 \%)$. The respondent then answers four questions in relation to the degree of the criminal involvement of their associates: (a) "Has this person ever committed a crime?" (b) "Does this person have a criminal record?" (c) "Has this person ever been to jail?" and (d) "Has this person tried to involve you in a crime?" Part A of the MCAA was used to calculate two measures of criminal associates. The first, "Number of Criminal Friends," was calculated by adding up the number of friends to which the participant had answered "yes" to any of the questions of criminal involvement. This meant the participant could indicate zero to four criminal associates. The second measure is the "Criminal Friend Index." This measure is calculated by assigning a number of one to four to the percentage of time options available for each identified associate. That number is then multiplied by the number of yes responses to the four questions of criminal involvement. Each of the resulting products is added together to produce the Criminal Friend Index. Overall scores for the Criminal Friend Index (CFI) therefore range from 0 to 64 , with higher scores reflecting an increased involvement with criminal associates. 
Part B is a 46-item assessment of attitudes consisting of four sub-scales: Attitudes toward Violence (12 items), Sense of Entitlement (12 items), Criminal Intent (12 items), and Attitudes toward Criminal Associates (10 items). Sample statements included: "It's understandable to hit someone who insults you" (Violence); "People are right to take what is owed to them, even if they have to steal it" (Entitlement); "For a good reason, I would commit a crime" (Antisocial Intent); "I know several people who have committed crimes" (Criminal Associates). Participants respond to a dichotomous choice of agree/disagree. Each endorsement of an antisocial statement (or rejection of a pro-social one) receives 1 point, whereas each rejection of an antisocial statement (or acceptance of a pro-social one) yields 0 points. For each sub-scale, scores are added up so that higher scores are reflective of increasingly antisocial attitudes.

Additionally, criminal behaviour was measured by level of recidivism. This was measured based on the frequency of incarcerations (How many times have you been in prison?).

Results

Descriptive statistics including means (M) and standard deviations (SD) for associations with criminal friends, recidivism, and the four subscales of criminal attitudes (attitudes toward violence, sense of entitlement, antisocial intent, attitudes toward criminal associates), are presented in Table 1 together with Cronbach's Alpha reliability scores.

Table 1. Descriptive statistics and reliability of measures included in current study ( $N=$ 133

\begin{tabular}{lrrrrr}
\hline Scale & M & SD & Range & $\begin{array}{l}\text { Possible } \\
\text { Range }\end{array}$ & \multicolumn{2}{c}{$\begin{array}{c}\text { Alpha }(\alpha) \\
\text { Alpach's }\end{array}$} \\
\hline Level of Recidivism & & & & $\mathrm{n} / \mathrm{a}$ & $\mathrm{n} / \mathrm{a}$ \\
Criminal Friends & 4.19 & 3.08 & $1-9$ & $\mathrm{n} / \mathrm{a}$ \\
Violence & 17.44 & 13.45 & $4-64$ & $0-64$ & .80 \\
Entitlement & 7.74 & 3.06 & $1-12$ & $0-12$ & .69 \\
Criminal Intent & 7.62 & 2.54 & $2-12$ & $0-12$ & .71 \\
Attitudes towards & 7.92 & 2.59 & $0-12$ & $0-12$ & .68 \\
Associates & 6.89 & 2.18 & $0-10$ & $0-10$ & \\
\hline
\end{tabular}


The relationships between criminal attitudes, recidivism, and associations with criminal friends were investigated using Pearson product-moment correlation coefficient (see Table 2). Preliminary analyses were performed to ensure no violation of the assumptions of normality, linearity and homoscedasticity. All correlation were significant ranging from $r=.17, p<.05$ to $r=.74, p<.001$.

Table 2. Correlations among all continuous variables (Note. Statistical significance: $\left.{ }^{*} \mathrm{p}<.05 ;{ }^{* *} \mathrm{p}<.01 ;{ }^{* * *} \mathrm{p}<.001\right)$

\begin{tabular}{llllll}
\hline Variables & $\mathrm{R}$ & $\mathrm{CF}$ & $\mathrm{V}$ & $\mathrm{E}$ & $\mathrm{Cl}$ \\
\hline Level of Recidivism (R) & --- & & & & \\
Criminal Friends (CF) & $.42^{* * *}$ & --- & & & \\
Violence (V) & $.34^{* * *}$ & $.41^{* * *}$ & --- & & \\
Entitlement (E) & $.26^{* *}$ & $.43^{* * *}$ & $.74^{* * *}$ & --- & \\
Criminal Intent (CI) & $.18^{*}$ & $.26^{* *}$ & $.51^{* * *}$ & $.51^{* * *}$ & -- \\
Attitudes towards Associates & $.17^{*}$ & $.45^{* * *}$ & $.37^{* * *}$ & $.28^{* * *}$ & $.45^{* * *}$ \\
\hline
\end{tabular}

The model shown in Figure 1 was tested using Mplus version 6 (Muthén \& Muthén, 2010) as a path model.

Figure 1. Conceptual path model of recidivistic behaviour. Note: $V=$ Attitudes towards Violence, $\mathrm{E}=$ Entitlement, $\mathrm{I}=$ Criminal Intent, $\mathrm{A}=$ Attitudes towards Criminal Associates, $C F=$ Associations with Criminal Friends, $\mathrm{REC}=$ Criminal Behaviour (Recidivism)

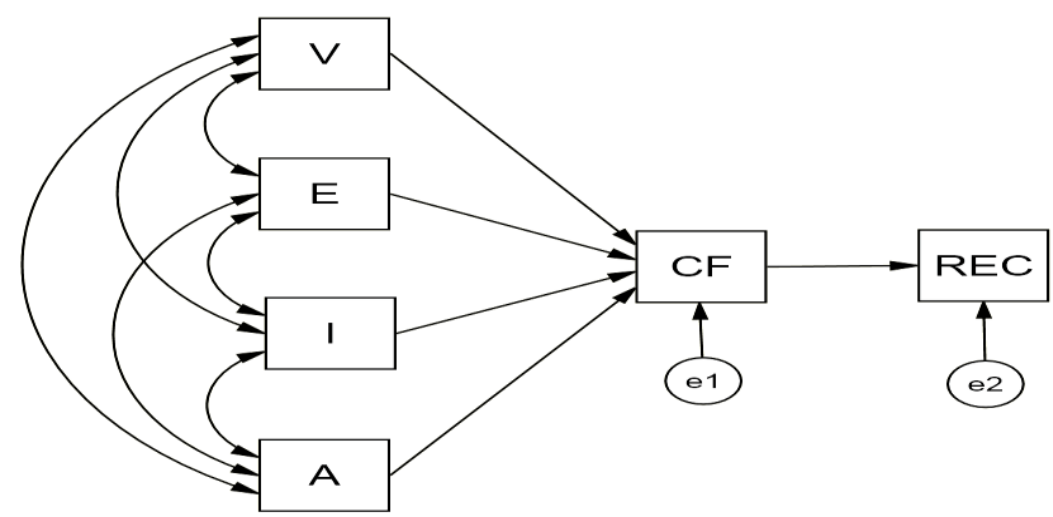


Table 3. Standardized and unstandardized regression paths and $R^{2}$ (with standard errors) for the specified path model (Note. Statistical significance: ${ }^{* *} p<.01 ;{ }^{* * *} p<$ $.001)$.

\begin{tabular}{llll}
\hline Variables & $\beta$ & $B$ & SE \\
\hline Direct Influence & & & \\
Violence ==> Criminal Friends & .11 & .46 & .41 \\
Entitlement ==> Criminal Friends & $.30^{* * *}$ & 1.59 & .52 \\
Intent ==> Criminal Friends & -.11 & -.55 & .45 \\
Associates ==> Criminal Friends & $.37^{* * *}$ & 2.29 & .49 \\
Criminal Friends ==> Recidivism & $.42^{* * *}$ & .10 & .02 \\
Indirect Influence & & & \\
Violence ==> Recidivism via Criminal Friends & .04 & .04 & .04 \\
Entitlement ==> Recidivism via Criminal Friends & $.13^{* *}$ & .15 & .06 \\
Intent ==> Recidivism via Criminal Friends & -.05 & -.05 & .04 \\
Associates ==> Recidivism via Criminal Friends & $.15^{* * *}$ & .22 & .06 \\
$R^{2}=.31, p<.00$ l (Criminal Friend Index); $R^{2}=.17, p<.05$ (Recidivism) & \\
\hline
\end{tabular}

Table 3 presents both absolute and comparative fit indices for each model. The chisquare ( $\left.\chi^{2}\right)$ statistic investigates the difference between the empirical model and the actual model. Ideally there should be no statistically significant difference between the empirical and the actual model to indicate a good fitting model. The Comparative Fit Index (CFl; Bentler, 1990) and the Incremental Fit Index (IFI; Bollen, 1989) are measures of how much better the model fits the data compared to one where no relationships exit. For these indices, values above .90 indicate a good fit (Bentler, 1990; Hu \& Bentler, 1999). In addition, two more absolute indices are presented; the root mean-square residual (RMSR) and the root mean-square error of approximation (RMSEA). These indices measure the average difference between the null and alternate models per element of the variance - covariance matrix and, thus, give relatively different information from the other indices. Ideally, these indices should be less than .05 however values of less than .08 also suggest adequate fit (Bentler, 1990; Hu \& Bentler, 1999). Findings suggest that the overall fit of the specified model (Figure 1) provided a good fit of the data. All indices show significant fit with $\chi 2=6.04, \mathrm{df}=4, \mathrm{p}=.20 ; \mathrm{RMSEA}=.06(90 \% \mathrm{Cl}=.00-.15) ; \mathrm{SRMR}=.04 ; \mathrm{CFI}=.96 ;$ and $\mathrm{TLI}$ $=.92$. Table 3 reports the standardized and unstandardized direct and indirect regression paths. As can be seen, sense of entitlement $(\beta=.30, p<.001)$ and attitudes towards criminal associates $(\beta=.37, \mathrm{p}<.001)$ have a positive, moderate and statistically significant effect on associations with criminal friends. Furthermore, 
statistical analysis also reported a direct moderate-to-strong impact of associations with criminal friends on criminal behaviour $(\beta=.42, \mathrm{p}<.001)$. In relation to the indirect effect of the four components of criminal attitudes on criminal behaviour, current findings suggest that there is a weak, positive, indirect impact of entitlement and attitudes towards criminal associates on criminal behaviour through associations with criminal friends.

\section{Discussion}

The primary objective of this research project was to further elucidate the relationship between criminal attitudes, criminal friends, and criminal behaviour using a sample of Polish prisoners. These three variables have long been viewed as important by social psychologists and criminologists in understanding criminal or antisocial behaviours. Although much empirical research has examined the predictive role of criminal attitudes and associations with criminal friends on criminal behaviour, no research to this point has examined the possible mediating role that associations with criminal friends' have on the relationship between criminal attitudes and criminal behaviour. The current study sought to redress this deficiency in the existing social psychological and criminological research by empirically investigating this hypothesised relationship within a sample of Polish recidivistic male prisoners who were all incarcerated for violent offences.

The proposed mediation model tested was found to be an excellent fit of the observed data, with each of the respective fit indices exceeding the criteria for a good fitting model, with the exception of the RMSEA value which was found to be just slightly above the 0.05 cut-off point for a good fitting model, and within the range of a moderate fitting model. The model was found to explain $31 \%$ of variance in associations with criminal friends, and $17 \%$ of variance in criminal behaviour.

Analyses revealed that sense of entitlement and attitudes toward criminal associates had a statistically significant relationship with the hypothesised mediating variable of associations with criminal friends. Both of these relationships were positive and in the moderate range. Associations with criminal friends were also found to be a statistically significant predictor of criminal behaviour, and this relationship was positive, and moderate-to-strong. Such finding is not unique and is largely consistent with previously reported research data using American, Canadian and Swedish offender and non-offender sample. However, it adds to the multicultural criminological literature by showing that the same psychological pattern occurs in a Polish offender population. 
In terms of the main research question, the current findings provide the first empirical support for the proposed mediating role of associations with criminal friends between criminal attitudes and criminal behaviour. The effects of two components of criminal attitudes (sense of entitlement and attitudes toward criminal associates) on criminal behaviour were found to be mediated by the role of associations with criminal friends. The mediating effects, although weak $(\beta=0.13$ for sense of entitlement, and $\beta=0.15$ for attitudes towards criminal associates), were statistically significant and have important theoretical implications. This finding suggests that although an individual can acquire criminal-typical attitudes and beliefs and have such attitudes be both available and accessible within the cognitive structure, their mere presence or accessibility alone is insufficient to predict or give rise to criminal behaviour. Association with criminal friends appears necessary to give rise to criminal behaviours which are a behavioural manifestation of these underlying criminal attitudes. This finding is theoretically congruent with Sutherland's (1947) Differential Association Theory which explains the development of criminal behaviour as a result of a variety of association with other individuals who possess criminal attitudes and engage in criminal behaviours and the learning theories of criminality or delinquency (Akers, 1985; Akers et al., 1979) which describe the central role played by criminal associates in an individual's learning of how to commit criminal acts. However, the current research is the first empirical attempt to suggest that the relationship between how criminals think about their antisocial friends (attitudes toward criminal associates) and how they behave in a criminal context is mediated (or sometimes activated) by the presence of criminal friends. Attitudes toward criminal others measure a unique aspect of criminal associations. Measuring the level of identification and acceptance of criminal associates (attitudes) is viewed as important in reflecting the influence that criminal associates may have on the individual. This domain of attitudes has been previously shown to be relevant to recidivism and offence-based criteria by Simourd, (1997, 1999). Additionally, sense of entitlement and further recidivistic behaviour is mediated by criminal friends. This suggests that the cognition that "tells" criminals they have a right to do whatever they want is activated in the presence of criminal associates.

This study is not without limitations. The project was conducted in a retrospective manner thus making it impossible to determine whether or not the criminal attitudes reported by the participants in the study were present at the time they committed their crimes, or at least present to the same level of intensity. As per the findings of Rhodes (1979) it is known that individuals can enter a prison environment with low levels of criminal attitudes and, due to the social environment of the prison, such individuals can acquire and develop more deviant criminal attitudes. Future studies 
should seek to employ a prospective research designs or, within the confines of a correlational design, data should be gathered prior to or immediately upon an individual's incarceration in a prison. Such research designs would however have been premature given that no research has even been undertaken to investigate whether the role of associations with criminal friends serves as a mediating factor between criminal attitudes and criminal behaviour. Now that there is empirical evidence suggesting such a relationship future studies should consider more rigorous methodological designs. A second limitation that should be considered is that the sample comprised only male, recidivistic prisoners, and it is unknown whether or not the findings of the current study could be generalised to the wider criminal population.

Despite the study's limitations, the observed findings have potentially important implications. Our findings make a significant contribution to the criminological and social psychological literature by offering the first empirical evidence of the mediating role of criminal friends for the relationship between criminal attitudes (sense of entitlement and attitudes toward criminal associates) and recidivistic behaviour. These findings may expound upon the scientific communities understanding of the factors involved in the development of criminal recidivistic behaviour and possible targets of intervention to reduce levels of criminality. It is suggested that the intervention of criminal others may significantly stimulate the presence of criminal cognitive structure (criminal attitudes) in the decision making process which is reflected in criminal behaviour. Moreover, this project is the first one that translated the MCAA into Polish and applied it to a Polish recidivistic violent prison sample.

\section{References}

Agnew, R. (1991). The interactive effects of peer variables on delinquency. Criminology, 29(1), 47-72. doi:10.1111/j.1745-9125.1991.tb01058.x

Akers, R. (1977). Deviant behaviour: A social learning approach (2nd Ed.). Belmont: Wadsworth.

Akers, R. (1985). Deviant behaviour: A social learning approach (4th Ed.). Belmont: Wadsworth.

Akers, R. L., Krohn, M., Lanze-Kaduce, M., \& Radosevich, M. (1979). Social learning and deviant behaviour: A test of general theory. American Sociological Review, 44, 636-655. doi:10.2307/2094592 
Bäckström, M., \& Björklund, F. (2008). The measures of criminal attitudes and associates (MCAA): Further testing of structural and criterion related validity. Criminal Justice and Behavior, 35, 1398-1410. doi:10.1177/0093854808322239

Bandura, A. (1969). Principles of behaviour modification. New York: Holt, Rinehart \& Winston.

Bandura, A. (1989). Human agency in social cognitive theory. The American Psychologist, 44, 1175-1184. doi:10.1037/0003-066X.44.9.1175

Bandura, A., \& Walters, R. H. (1963). Social learning and personality development. New York: Holt, Rinehart, \& Winston.

Bentler, P. M. (1990). Comparative fit indices in structural models. Psychological Bulletin, 107, 238-246. doi:10.1037/0033-2909.107.2.238

Bollen, K. A. (1989). Structural equations with latent variables. New York: Wiley.

Conway, K. P., \& McCord, J. (2002). A longitudinal examination of the relation between co-offending with violent accomplices and violent crime. Aggressive Behavior, 28, 97108. doi:10.1002/ab.90011

Gendreau, P., Little, T., \& Goggin, C. (1996). A meta-analysis of the predictors of adult offender recidivism: What works! Criminology, 34(4), 575-608. doi:10.1111/j.17459125.1996.tb01220.x

Holsinger, A. M. (1999). Assessing criminal thinking: Attitudes and orientations influence behavior. Corrections Today, 61, 22-25.

Hu, L., \& Bentler, P. M. (1999). Cutoff criteria for fit indexes in covariance structure analysis: Conventional criteria versus new alternatives. Structural Equation Modeling , 6 , 1-55. doi:10.1080/10705519909540118

Kaiser, G. (1997). Criminology (10th Ed.) Heidelberg: C. F. Muller.

Losel, F. (2003). The development of delinquent behaviour. In D. Carson \& R. Bull (Eds) Handbook of Psychology in Legal Context (2nd Ed). England: John Wiley and Sons, Ltd

Mills, J. F., \& Kroner, D. G. (1999). Measures of criminal attitudes and associates. Unpublished User Guide.

Mills, J. F., Kroner, D. G., \& Forth, A. E. (2002). Measures of Criminal Attitudes and Associates (MCAA): Development, factor structure, reliability, and validity. Assessment, 9 , 240-253. doi:10.1177/1073191102009003003 
Monahan, K. C., Steinberg, L., \& Cauffman, E. (2009). Affiliation with antisocial peers, susceptibility to peer influence, and antisocial behaviour during the transition to adulthood. Developmental Psychology, 45(6), 1520-1530. doi:10.1037/a0017417

Muthén, L. K., \& Muthén, B. O. (2010). Mplus User's Guide (Sixth ed.). Los Angeles, CA: Muthen \& Muthen.

Reiss, A. J., \& Farrington, D. P. (1991). Advancing knowledge about co-offending: Results from a prospective longitudinal survey of London males. The Journal of Criminal Law \& Criminology, 82, 360-395. doi:10.2307/1143811

Rhodes, M. L. (1979). The impact of social anchorage on prisonization. Dissertation Abstracts International, 40, 1694A. (UMI No. 79-19, 101).

Simourd, D. J. (1997). The Criminal Sentiments Scale-Modified and Pride in Delinquency scale: Psychometric properties and construct validity of two measures of criminal attitudes. Criminal Justice and Behavior, 24, 52-70. doi:/10.1177/0093854897024001004

Simourd, D. J. (1999). Assessment of criminal attitudes: Criterion-related validity of the Criminal Sentiments Scale-Modified and Pride in Delinquency scale. Criminal Justice and Behavior, 26, 90-106. doi:/10.1177/0093854899026001005

Stevenson, S. F., Hall, G., \& Innes, J. M. (2003). Socio-moral reasoning and criminal sentiments in Australian men and women violent offenders and non-offenders. International Journal of Forensic Psychology, 1, 111-119.

Sutherland, E. H. (1947). Criminology (4th Ed). Philadelphia: Lippincott.

Sutherland, E. H., \& Cressey, D. R. (1978). Criminology (8th Ed). Philadelphia: Lippincott. Sutherland, E. H., Cressey, D. R., \& Luckenbill, D. F. (1992). Principles of criminology. Dix Hills, N.Y.: General Hall.

Thornberry, T., Lizotte, A., Krohn, M., Farnworth, M., \& Jang, S. (1994). Delinquent peers, beliefs, and delinquent behaviour: A longitudinal test of interactional theory. Criminology, 32(1), 47-83. doi:/10.1111/j.1745-9125.1994.tb01146.x

Warr, M. (1993). Age, peers and delinquency. Criminology, 31 (1), 17-40. doi:/10.1111/j.1745-9125.1993.tb01120.x

Warr, M. (2002). Companions in crime. Cambridge, UK: Cambridge University Press.

Warr, M. (2005). Making delinquent friends: Adult supervision and children's affiliations. Criminology, 43(1), 77-106. doi:/10.1111/j.0011-1348.2005.00003.x 
Warr, M., \& Stafford, M. (1991). The influence of delinquent peers: What they think or what they do? Criminology, 29(4), 851-866. doi:/10.1111/j.1745-9125.1991.tb01090.x

\section{About the Authors}

Daniel Boduszek is a researcher in criminal psychology with a special interest in application of advanced statistical analysis and methodology to the field of criminal/social psychology. He is also the Editor-in-Chief and the Founder of the Journal of Criminal Psychology. (e-mail: d.boduszek@interia.eu)

Philip Hyland is a researcher in Counselling/Clinical Psychology, Cognitive Behavioural Therapy, and Abnormal Psychology. He is also the Co-Founder and the Associate Editor of the Journal of Criminal Psychology.

Jacek Pedziszczak is an educational officer in Nowogard High Security Prison, Poland. His main area of interest includes recidivism and prisonization.

Krzysztof Kielkiewicz is a research assistant and PhD student in All Hallows College, Republic of Ireland. 